\title{
Effect of Market Expansion Acquisition Motive on Financial Performance of Manufacturing Companies in Kenya: A Case Study of Brookside Dairies Limited
}

\author{
Isack Odiwuor Abiero', Dr. Agnes Njeru² \\ ${ }^{1}$ Jomo Kenyatta University and Technology, \\ P.O. Box 620000-00200, Nairobi, Kenya \\ $+254725897919$ \\ isackabiero@yahoo.com \\ ${ }^{2}$ Jomo Kenyatta University and Technology, \\ P.O. Box 620000-00200, Nairobi, Kenya \\ $+254720880195$
}

\begin{abstract}
Many companies are acquiring other companies with a motive to expand its market. This study sought to determine whether the market expansion motives have effects on financial performance of the companies. The study was conducted at the Brookside Dairies Ltd headquarters at Ruiru, which was purposively sampled due to its recent past business history of acquiring other dairy firms. The study focused also the company's acquired targets including Ilara Dairy Ltd, Delamare Ltd, Buzeki Dairy Ltd and Spin Knit Dairy Ltd. Three years pre and post-acquisition financial statements of the company was also examined and its key financial ratios computed to determine pre and post-acquisition financial performance. A descriptive research design was adopted. The study used a sample size of 40 respondents who were all the management employees working in the case company and acquired targets. The choice and identification of key informants was sampled purposively as they hold key information of the company's business information and strategies. Questionnaire was the main instrument for data collection. However, financial documents from the company also provided secondary data. Analysis and interpretation of the data was done using both qualitative and quantitative methods according to research objectives and research questions. The data collected was summarized, classified, tabulated and analyzed qualitatively. Data was then presented using tables, charts and percentages. The study findings revealed that market expansion motive have effect on the financial performance of manufacturing company.
\end{abstract}

Keywords: market expansion motive, acquisition, financial performance, manufacturing company, Brookside Dairies Limited

\section{Introduction}

Globally, business world has continuously experienced increased acquisitions over the last decade. Various reasons have driven firms to undertake in acquisitions. Growing business confidence, consumer demand and improving economic conditions in the region have whetted business executives' appetite for firms in the technology, mining, financial services and even production and manufacturing sectors (Korir, 2007). Acquisitions are continuously being adopted for progressive company competitiveness by expanding market share. Acquisitions are used to increase the company's portfolio as a marketing management strategy. Additionally, to enable companies penetrate to new geographical markets to support growth by capitalizing on economies of scale and increase on customer base among other reasons (Kemal, 2011).

The motives for acquisitions are; increased market share and revenues, economies of scale, synergy, agency, hubris, taxation, agency, efficiency, widen geographical areas among other rationale. Investors may expect acquisitions to deliver enhanced market power. Corporations are undertaking various strategies in efforts to improve financial performance.
Financial performance is paramount to the success of any organization as it reflects the financial health of companies in the market and the performance as compared to other players in the industry. Many of the existing studies (such as, Healy et al. 1992; Grabowski et al., 1995; Switzer, 1996; Waldfogel and Smart, 1994; Vander, 1996) empirically support the proposition that acquisition lead to better financial performance of the firms. Contrary to this, there are also studies (such as, Dickerson et al., 1997; Ravenscraft and Scherer, 1987a and 1987b; Mueller, 1985; Ghosh, 2001) that report results at odds with the view that acquisitions and acquisitions improve corporate performance. Further, Ikeda and Doi (1983), Kumar (1984), Geroski (1988), Odagiri (1992) also find either such negative results or little changes in operating performance following acquisition. Nonetheless, empirical evidence on acquisitions has also suggested that acquisitions might fail because of over-optimistic expectations of benefits and underestimation of postintegration difficulties like lack of market or technology relatedness, business culture clashes, and many more. (Šević, 1999).

Recent corporate merger and acquisition activities witnessed in the Kenyan economy is a sign that companies are increasingly accepting this takeover option as a means towards developing their corporate strategies either in the 


\section{International Journal of Science and Research (IJSR) \\ ISSN (Online): 2319-7064}

Index Copernicus Value (2013): 6.14 | Impact Factor (2015): 6.391

country or in the industry. Besides, the move towards regional integration has indeed sparked a flurry of cross regional expansion which has seen various company's not only use cross-listing across various markets as a means of increasing regional presence but also as a way marked to increase regional acquisitions and buyouts. This has made several Kenyan companies to venture out of the country in cross border acquisitions (Inoti, Onyuma \& Muiru, 2014). This leaves a gap for scholars to try to unearth if the driver to acquisitions plays a role in the change of financial performance of the acquiring company.

\section{Statement of the Problem}

Acquisitions seem to be popular to the corporate players involved. Numerous studies from around the world have failed to agree on whether acquisitions improve the acquiring firm's financial performance. Some studies show that there is improved post acquisition financial performance for acquiring firms (Azhagaiah and Kumar 2011; Ramaswany and Waegelein, 2003; Kithinji, 2007; Korir, 2006). However, other studies show that acquisitions have no financial benefits for the acquiring firms (Selcuk and Yilmaz, 2011; Ndura, 2010).

Little has been conducted on the effect of acquisitions motives or strategies on performance of firms especially in the Manufacturing industries. These past studies have led to conflicting results that make the effect of acquisition as a business strategy inconclusive.

It is therefore essential to study the effects that acquisition motives have on financial performance of corporate manufacturing organizations, hence the aim of this study. Rather than being used as strategic management tool, it is important to establish also the impact of acquisitions motives on liquidity, profitability and solvency.

\section{General Objective of the Study}

To assess the effect of market expansion acquisition motive on financial performance of manufacturing companies in Kenya.

\section{Specific objectives of the study}

i) To determine the effect of new markets acquisition on financial performance of manufacturing companies in Kenya.

ii) To evaluate the effect of market dominance/monopoly on financial performance of manufacturing companies in Kenya.

iii) To establish the effect of increased market power on financial position of manufacturing companies in Kenya.

\section{Literature Review}

\section{Market Power Theory}

Market power may be interpreted as the ability of a firm to control the quality, price, and supply of its products as a direct result of the scale of their operations. Because acquisitions promise rapid growth for the firm, it can be viewed as a strategy to extend control over a wider geographical area and enlarge the trading environment (Leigh and North, 1978). Therefore, the market power theory can serve as an explanation for horizontal and vertical acquisitions.

Economic theory of oligopoly and monopoly identifies the potential benefits to achieving market power, such as higher profits and barriers to entry. The market power theory therefore explains the mass of horizontal acquisitions and the increasing industrial concentration that occurred during the 1960s. For example, in the United Kingdom, evidence shows that acquisitions "were responsible for a substantial proportion of the increase in concentration over the decade 1958-1968 (Hart and Clarke, 1980)." This wave of horizontal acquisitions gradually decreased during recent years, primarily because of antitrust legislation introduced by many countries to protect the market from undue concentration and subsequent loss of competition that results. Utton (1982) noted that tacit collusion can create a situation in which only a few companies with oligopolistic power can share the profits by noncompetitive pricing and distorted utilization and distribution of resources at the expense of society as a whole. However, horizontal acquisitions are not the only target of the antitrust authorities and vertical and conglomerate acquisitions are of concern. This is because a "large firm's power over prices in an individual market may no longer depend on its relative size in that market but on its overall size and financial strength (Utton, 1982)."

\section{Conceptual Framework}

The study adopted the following conceptual framework:

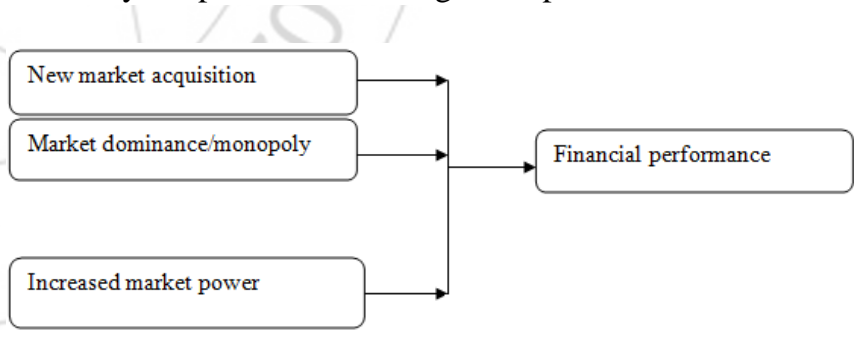

Independent Variable Dependent Variable

Source: Author 2016

Conceptual framework

\section{Market Expansion Motive}

Increased market power is defined as the ability of a firm or group of firms to raise prices above the level that would prevail under competitive conditions (DePamphilis, 2005). The ability to exclude competitors is also seen as a result of excessive market power. The scope of enhancement of market power is associated with industry concentration, product differentiation, entry barriers and cost advantages. The market power acquisition drive in horizontal acquisitions is the most controversial one. However, market power is not exclusive to horizontal acquisitions. This can be through unilateral effect, coordinated effect 


\section{International Journal of Science and Research (IJSR) \\ ISSN (Online): 2319-7064}

Index Copernicus Value (2013): 6.14 | Impact Factor (2015): 6.391

(collusion), raising entry barrier, spreading portfolio and obtaining multimarket contact etc.

Market dominance or monopoly, acquisitions are executed to increase market positioning and to gain market control power. However, Trautwein (1990), summarizes that the monopoly theory's records appears to be scanty as most studies shows that the main reason for acquisition is not to achieve monopoly or dictate the market. Evidence of monopolistic consequences of merger can be identified by observing target firm, acquirer firm and the rival reactions. As an improvement of market positioning is to be achieved, there should be a positive gain to target and acquirer shareholders.

New and already established markets can be fast-tracked by acquisition. When two firms or companies merge, each firm acquires the customer base of each other. In some cases, the acquired customer base may represent a market that was previously unavailable. The acquired merger may be of different product/service line or level, and this new arrangement may provide a more balanced customer base. Isaac et al (2013), mention that market motive aims at entering new markets in new areas by acquiring already established firms as the fastest way or as a way to gain entry without adding additional capacity.

\section{Research Methodology}

A case study research approach was employed in order to enable the researcher carry out in-depth investigations of effects of market expansion motive of acquisition on the financial performance of a company because this brought the researcher to an understanding of the complex issue and can extend experience or add strength to what is already known through previous researches.

The study targeted the 40 management staff of Brookside Dairies Ltd and the acquired targets including Ilara Dairy Ltd, Delamare Ltd, Buzeki Dairy Ltd and Spin Knit Dairy Ltd. This is because; these managers are the one who are responsible for designing effective strategic plans in the organization where acquisition is one of the strategic management tools in an organization. This population is more consistent as possible with the purpose of the study (Mugenda and Mugenda, 2003). This is where the sample was drawn and sample frame was a list of 40 management employees within the larger company and its acquired affiliates.

Table 1: Sample frame

\begin{tabular}{|c|c|}
\hline Target Population & Sample Size (frequency) \\
\hline Brookside HQ & 11 \\
\hline Buzeki Dairies & 08 \\
\hline Spinknit Dairies & 06 \\
\hline Ilara Dairies & 08 \\
\hline Delamere Dairies & 07 \\
\hline Total & 40 \\
\hline
\end{tabular}

Source (www.brooksidedairies.com)

The study area was purposively chosen because Brookside Dairies is a company that has recently acquired much other organization within the same industry. The study targeted all management staff of Brookside Dairies Ltd and its acquired targets. Since the target population was manageable, the study adopted purposive sampling where all the 40 management employees were included in the sample, by virtue of their managerial responsibility.

In order to meet the objective of the study, questionnaires developed by the researcher were used to collect primary data from the respondents who were asked the same questions in the same order. The questionnaires which were standardized and completely predetermined contained both open and closed ended questions. The study variables and instruments for data collection were scrutinized and approved by an expert, to ascertain their content validity after pilot testing.

Secondary data was used, extracted from previous research reports and company's financial documents review. Data from financial statements included; current assets, current liabilities, total liabilities, net worth and total assets. Primary data was collected through the administration of questionnaire to the respondents that were dully filled.

Qualitative analysis was done on the information collected from the results of the questionnaires. Quantitative analysis included descriptive statistical technique which complimented the use of frequencies, mean and percentages that was summarized and presented using tables, graphs and charts. This was used to meaningfully describe the distribution of scores or measurements using indices like mean and mode.

\section{Results and Discussions of the Findings}

The researcher conducted a study on 40 respondents who were each issued with a self administered questionnaire. Only 35 questionnaires were filled and returned by the respondents translating to a respondent rate of $87.5 \% .46 \%$ of the respondents were from the top level management, $43 \%$ of the were from the middle level management, whereas $11 \%$ were from the entry level management.

Majority of the management officers have been with the organization for more than six years. The respondents who have worked for the company for less than 2 years were $9 \%$, between 2-5 years were $28 \%$, between 6-10 years were $37 \%$ and those above 10 years were $26 \%$ (as shown in the figure below). This implies that those who have worked for the organization understood the organization's culture and its operations thus were better placed to lead the organization to the better direction using the acquisition strategy. The study revealed that a greater number of the respondents have been holding the positions they currently are in for less than 5 years. Twelve (34\%) respondents reported that they have held the positions they are in for less than 2 years. Fourteen (40\%) respondents have held their current positions for duration of between 25 years while seven $(20 \%)$ respondents have held their current position for a period of between 6-10 years. Only two (6\%) respondents have occupied their current management positions for more than 10 years. This report suggest that with the recent acquisitions of other competing companies, many positions were created and

\section{Volume 5 Issue 5, May 2016}




\section{International Journal of Science and Research (IJSR) \\ ISSN (Online): 2319-7064}

Index Copernicus Value (2013): 6.14 | Impact Factor (2015): 6.391

those who are well conversant with the organization's culture and operations appointed to those positions.

This study sought to know from the respondents if the main reason as to why a company goes to acquire another company is to expand its market. $23(66 \%)$ respondents believed that expanding the market is the main reason management of a firm initiates an acquisition strategy to occupy the market base initially occupied by the competitor. $10(28 \%)$ respondents also believed in this but opined that there are other reasons that may make a firm go to marry another firm. $2(6 \%)$ respondents neither agreed nor disagreed as they were not so sure about what motive a firm may have into marrying another. An expanded market enables more sales that translate to an increased profitability. It also creates market leadership and the firm will have an upper hand in decision making in the industry especially on pricing.

The finding on market expansion strategies shows that a firm that acquiring a bigger market enables a firm to increase its market power to control prices over the competitors. This comes about through negotiation with suppliers and channel members. Market deregulation and a wave of privatization had also led to expansion of markets through acquisition (Mitchell and Mulherin, 1996). Over $90 \%$ of the respondents confirmed this and concurred that this strategy is a quicker way of entering new and already established markets that were already occupied by the acquired entity. In a new market, such as another country, the acquirer will find this strategy the best as it will use the acquired firm's resources like license and brand name to market its introduced products. This will increase sales and enhance profitability.

Ability to control the market by virtue of bigger market share enables the firm to dominate market activities and excludes competitor hence leading to monopoly. This is possible as the market leader has the power to sway every decision in the industry such as lowering prices and this kills other small players. However, in Kenya, this practice is controlled under the Competition Authority of Kenya to control unfair competitions. This was the main reason as to why a good number of respondents, about $47 \%$, neither were unsure nor disagreed.

An expanded market brings about an increase in sales and this is the main reason a firm will go into acquiring another firm. A large coverage area also means more customers to be served and this will lead to more movement of inventory hence an increase in profitability level. $97 \%$ of the respondents were in agreement with this while only $3 \%$ unsure.

\section{Conclusion}

The result of the study has indicated that an expanded market is the main drive that enables a firm to acquire another firm. More than $90 \%$ of the respondents accepted this suggesting that an expanded market enables more sales and this will translate to an improved profit margin. However, this market leadership cannot be used to exclude other players in the industry and create monopoly as supported by majority of the respondents, claiming protection of the other players by Competition Authority of Kenya. This shows that this motive will affect financial performance positively.

The study therefore concludes that, Brookside Dairies Limited has been using this business strategy with a motive to expand its markets and improve its business efficiencies that has lead to more sales thus improving financial performance.

\section{Recommendation}

Some respondents claimed that the purchasing of the rivals by a big company might somehow lock out small players hence creating monopoly within the industry. This may kill the spirit of competition and allow customer exploitation on prices or quality of the products. With the creation of Competition Authority of Kenya by Competition Act No. 12 of 2010, to check on unfair competition, this agency ought to be given teeth in order to arrest and prosecute offenders.

\section{References}

[1] Bowman, E.H., and Singh, H. (1999). When Does Restructuring Improve Performance, California Management Review, Vol. 6, pg 34 - 54.

[2] Brandley, M., Desai, A. and Kim, E.H,(1988). Synergetic Gains from Corporate Acquisitions and their Division between the Stockholders of Targets and Acquiring Firms, Journal of Financial Economics, Vol. 21, pg 3-40.

[3] Crum, B., and Goldberg, G (1998). National Oil and Gas Policy Reforms, Journal of Financial Economics, Vol. 2, pg $261-300$.

[4] Gibbs, K.L. (2007). Accounting Management and Control, London, John Murray (Publisher) Ltd.

[5] Healy P M, Palepu KG and Ruback RS. (1992). Does corporate performance improve after acquisitions? Journal of Financial Economics, 31: 135-175.

[6] Hitt M A, Hoskisson R E, Johnson R A, Moesel D $\mathrm{D},(1996)$. The market for corporate control and firm innovation. Academy of Management Journal (5):1084-1119.

[7] Ismail, T.H., Abdou, A.A., and Annis, R.M. (2010). Exploring Improvements of Post- Merger Corporate Performance: The Case of Egypt, The Icfai University Journal of Business Strategy (Forthcoming). Vol. 1, Issue 1, pg 78-99.

[8] Jin, Z., Dehuan, J., and Zhigang, F. (2004). The Impact of Business Restructuring on Firm Performance - Evidence From Publicly Traded Firms in China, Academy of Accounting and Financial Studies Journal, Vol. 2, Issue 1, pg11-16.

[9] Kinshore, R.M. (2004). Financial Management, New Delhi, Taxman Allied Services Ltd.

[10] Kithinji, M. (2007). Effects of Acquisitions on Financial Performance of Non Listed Banks in Kenya. Unpublished MBA Thesis. University of Nairobi.

[11] Kithitu, J., Cheluget, J., Keraro V and Mokamba J. (2012). Role of Mergers and Acquisitions on the Performance of Commercial Banks in Kenya.

\section{Volume 5 Issue 5, May 2016}




\section{International Journal of Science and Research (IJSR) \\ ISSN (Online): 2319-7064}

Index Copernicus Value (2013): 6.14 | Impact Factor (2015): 6.391

International Journal of Management \& Business Studies. Vol. 4, Issue 2, pg 1 - 17

[12] Korir, E. (2006). Effects of Acquisitions on Financial Performance of Companies listed at the NSE. Unpublished MBA Thesis. University of Nairobi.

[13] Kothari, C. R (2006). Research Methodology Methods and Techniques (2 ${ }^{\text {nd }}$ Edition) New Delhi Wishwa Prakashan.

[14] Koul, L. (1993). Methodology of Education Research. New Delhi: Vikas Publishing.

[15] Mishra, P. \& Chandra, T. (2010). Mergers, Acquisitions and Firms ${ }^{e c}$ Performance: Experience of Indian Pharmaceutical Industry, Eurasian Journal of Business and Economics, 3(5), pg 111-126.

[16] Mugenda, M. O and Mugenda, G. A. (2003). Research Methods: Qualitative and Quantitative Approaches, Nairobi Kenya, ACTS Press.

[17] Roll, R. (1986): The Hubris Hypothesis of Corporate Acquisitions, Journal of Business, 59(2), 197-216.

[18]Roller L-H, Stennek, J., and Verboven F. (2006): "Efficiency Gains from Acquisitions," in European Acquisition Control: Do We Need and Efficiency Defence, ed. by Ilzkovitz and Meiklejohn. Edward Elgar. Athens, James Publishers.

[19] Selvam, M., Babu, M., Indhumathi, G. and Ebenezer, B. (2009). Impact of Mergers on Corporate Performance of Acquirer and Target Companies in India, Journal of Modern Accounting and Auditing, Vol. 5(1), pg $55-64$.

[20] Singleton Jr. R.A.; Straits, B.C. and Straits, M.M. (1993). Approaches to Social Research. New York: Oxford University Press

[21] Tichy, G. (2001): "What do we know about success and failure of acquisitions," Journal of Industry Competition and Trade, 4(1), 347-394.

[22] Tirole, J. (1988): The Theory of Industrial Organization, Cambridge, MIT Press.

[23] UNCTAD (2000): World Investment Report 2000: Cross-border Acquisitions and Acquisitions and Development. New York.

[24] Yin, R.K. (1997). Case Study Research: Design and Methods. Newbury Park: Sage 